\title{
Melatonin Ameliorates Developmental Landmarks Induced by Gestational and Lactational Coexposure to Chlorpyriphos and Cypermethrin in F1 Male Rats
}

Muftau Shittu ( $\square$ mshittu@abu.edu.ng )

Ahmadu Bello University

Suleiman Ambali

University of llorin

Joseph Ayo

Ahmadu Bello University

Umaru Kawu

Ahmadu Bello University

Motunrayo Akande

University of Abuja

\section{Research Article}

Keywords: Chlorpyriphos, Cypermethrin, Developmental toxicity, Melatonin, Amelioration

Posted Date: December 17th, 2021

DOI: https://doi.org/10.21203/rs.3.rs-1100972/v1

License: (c) (1) This work is licensed under a Creative Commons Attribution 4.0 International License.

Read Full License 


\section{Abstract}

The ameliorative potentials of melatonin $(\mathrm{ML})$ on developmental changes evoked by gestational and lactational co-exposure to chlorpyriphos (CP) and cypermethrin (CY) was investigated in male Wistar rats. Pregnant dams were divided at random into 6 groups of 10 animals each and treated orally by gavage from gestation day 1 to postnatal day 21 with the following regimens: The DW, SO and ML groups were administered distilled water $(2 \mathrm{ml} / \mathrm{kg})$, soya oil $(2 \mathrm{ml} / \mathrm{kg})$ and melatonin $(0.5 \mathrm{mg} / \mathrm{kg})$, respectively; CC group was co-administered CP $(1.9 \mathrm{mg} / \mathrm{kg})$ and $\mathrm{CY}(7.5 \mathrm{mg} / \mathrm{kg})$; MC group was pretreated with $\mathrm{ML}(0.5$ $\mathrm{mg} / \mathrm{kg}$ ) and followed by co-administration of $\mathrm{CP}$ and $\mathrm{CY}$ while the $\mathrm{CM}$ group was administered $\mathrm{CP}$ and $\mathrm{CY}$ and then treated with $\mathrm{ML}$. We evaluated the developmental parameters on the F1 generation male rats at different postnatal intervals following parturition. Alterations in litter size and weight, number of live/dead pups, anogenital distance, crown-rump length, time of eye and ear openings, and testicular descent induced by gestational and lactational exposure to $\mathrm{CP}$ and $\mathrm{CY}$ in $\mathrm{F} 1$ male rats were mitigated by pre- and post-administration of ML. These curative and prophylactic potentials of ML may be partly attributed to its widely known antioxidant property.

\section{Introduction}

The use of pesticides in both agricultural and non-agricultural settings, as a means of increasing crop yield and eradication of vector and vector-borne diseases, has gained wide acceptance ${ }^{1}$. However, this has resulted in an increased incidence of pesticide-related illnesses in both man and animals, and alteration of the ecosystem ${ }^{2}$. To curtail the increased resistance by the pest to single insecticide application, farmers and other pesticide applicators are engaged in the use of insecticide mixture. Although this has increased their bioefficacy, it is also accompanied by novel challenges relating to toxicity and safety to the environment. Women, including pregnant mothers, constitute a significant percentage of the farming population, especially in many developing countries ${ }^{3}$. Therefore, there is an increased likelihood of contact with pesticides by pregnant mothers during farming engagements. This poses a risk to the developing embryo, especially that several studies have shown that certain pesticides including organophosphates (OPs) ${ }^{4,5}$, pyrethroids ${ }^{6}$ and their combination ${ }^{7}$ are developmental toxicants.

Chlorpyriphos (CP) (0-0-diethyl-0-3,4,6-trichloro-2-pyridyl phosphorothionate is one of the most widely used OP pesticides in agricultural and domestic pest control ${ }^{8,9}$. Its use has increased rapidly since its introduction in 1965 partly due to the ban placed on chlordane, a termiticide, in $1988^{8}$. Exposure to $\mathrm{CP}$ during pregnancy is a major health issue since this pesticide readily crosses the placenta ${ }^{10}$ and, as such, has the potential to cause adverse health consequences on the developing organism ${ }^{11}$. Studies in laboratory animals ${ }^{12}$ and humans ${ }^{13}$ have shown that $\mathrm{CP}$ causes a fetotoxic and teratogenic effect. Like other OP insecticides, the main mechanism of systemic toxicity is due to irreversible inhibition of acetylcholinesterase (AChE), resulting in cholinergic toxicity ${ }^{14}$. However, toxicity does occur at levels that do not ablate AChE activity, indicating other mechanisms are involved. One of the other mechanisms implicated in OP poisoning is oxidative stress. 
Cypermethrin (CY) is a class II synthetic pyrethroids that have been widely applied in agriculture, forestry, domestic, horticulture and veterinary medicine ${ }^{15}$. Several studies have described the developmental toxicity of $C Y^{16,17}$. Inhibition of central transmission through prolongation of sodium ion channels in the nerve cell membrane and induction of oxidative stress have been implicated in its toxicity ${ }^{17}$.

Melatonin (N-acetyl-5-methoxytriptamine) is a hormone produced from the pineal gland. It is produced during the dark phase of the circadian cycle and is a highly conserved antioxidant molecule ${ }^{18}$. Although it plays a significant role in many body processes, its role as an antioxidant and free-radical scavenger ${ }^{19}$, and its involvement in the enhancement of body antioxidant systems have recently been receiving significant attention ${ }^{20,21}$. Therefore, the present study investigated the ameliorative potentials of melatonin on developmental changes evoked by gestational and lactational co-exposure to $\mathrm{CP}$ and $\mathrm{CY}$ in male Wistar rats.

\section{Methodology}

\section{Management of Experimental Animals}

Seventy-two (72) 12 weeks old adult nulliparous female and 72 male Wistar rats weighing between 140160 grams were used for this experiment. They were bred and housed in the Department of Veterinary Anatomy Research Laboratory, Ahmadu Bello University, Zaria, Nigeria. They were fed pellets made from grower's mash (Vital Feeds Ltd., Jos, Nigeria), and were given access to drinking water ad libitum. Ethical approval was obtained from the Ahmadu Bello University Committee on Animal Use and Care (Ethical Approval no: ABUCAUC/2020/002). All experiments were perfomed in accordance with relevant guidelines and regulations. The reporting in the manuscript follows the recommendation in the ARRIVE ${ }^{22}$ (Animal Research Reporting In Vivo Experiments) guidelines.

\section{Pesticide, Melatonin and Soya Oil Preparation}

Commercial grade CP (20\% E.C. TERMICOT ${ }^{\circledR}$, Sabero Organics, Gujarat, India) and CY $(10 \%$ EC, GLOBATHRIN ${ }^{\circledR}$, Heranba Industries Limited, Vapi, India) were obtained from a reputable agrochemical outlet in Kaduna, Nigeria. Melatonin (ML, 3 mg/Tablet; Nature Made Nutritional Product ${ }^{\circledR}$, USA) was obtained from a reputable pharmaceutical outlet in Ilorin, Nigeria. Soya oil (SO; Grand Pure Soya Oil, Grand Cereals Limited, Jos, Nigeria) was obtained from a reputable grocery store in Zaria, Nigeria. Chlorpyriphos (CP) was dissolved in SO to make a $1 \%$ working solution, while cypermethrin (CY) and melatonin (ML) were dissolved in distilled water to make $1 \%$ and $1.5 \mathrm{mg} / 2 \mathrm{ml}$ stock solutions, respectively.

\section{Animal breeding and dosing protocol}

Seventy-two sexually mature female nulliparous Wistar rats weighing 140-160 grams were bred with 72 adult males overnight to obtain 60 pregnant dams in a 1:1 mating scheme ${ }^{23}$. Pregnancy was confirmed 
by the presence of vaginal plug or sperm cells using vaginal swab microscopy in the morning hours $(0.700 \mathrm{hrs})$ after mating. The day the copulation plugs/spermatozoa were found in the vagina was designated as Day 1. The sixty pregnant dams were thereafter divided at random into 6 groups of 10 animals each. The DW, SO and ML groups were given distilled water $(2 \mathrm{ml} / \mathrm{kg})$, soya oil $(2 \mathrm{ml} / \mathrm{kg})$ and $\mathrm{ML}$ $(0.5 \mathrm{mg} / \mathrm{kg})^{24}$, respectively. The CC group was co-administered CP $\left(1.9 \mathrm{mg} / \mathrm{kg} \sim 1 / 50^{\text {th }}\right.$ of the $\left.\mathrm{LD}_{50}\right)$ and CY $\left[7.5 \mathrm{mg} / \mathrm{kg} \sim 1 / 50^{\text {th }} \text { of the } \mathrm{LD}_{50}\right]^{24}$; The MC group was pretreated with $\mathrm{ML}(0.5 \mathrm{mg} / \mathrm{kg})$ and then coadministered $\mathrm{CP}$ and $\mathrm{CY}$, respectively, 30 minutes later; The $\mathrm{CM}$ group was co-administered $\mathrm{CP}$ and $\mathrm{CY}$, followed by $\mathrm{ML}, 30$ minutes later. The pregnant dams were administered the regimens by gavage once daily from gestation day 1 (GD 1) to postnatal day (PND) 21. The doses of the insecticides were chosen after a series of pilot studies, taken into cognizance, the objective of mimicking environmental and repeated occupational exposure. Following their normal parturition by the pregnant dams, the pups were evaluated for some developmental parameters. To avoid bias, the services of two assessors blinded to the experimental design were sought to evaluate the effect of treatments on the following developmental parameters:

\section{i. Litter size}

The litter size was determined on PND 0 by counting and recording the number of pups delivered by each dam.

\section{ii. Number of live and dead pups}

The number of live and dead pups in each litter was evaluated on the day of birth (PND 0). Following delivery, the number of live and dead pups were physically counted and recorded for each of the dams.

\section{iii. Litter weight}

The evaluation of the litter weight of each pup was done at PND 0 and subsequently on PNDs 4, 7, 14 and $21^{25}$ using a precision weighing balance (Mettler ${ }^{\circledR} \mathrm{P} 161$, Switzerland). The pups from each treatment group were weighed individually, and the mean ( \pm SEM) of the bodyweight of the pups from each of the dams in a group was calculated.

\section{iv. Determination of anogenital distance}

The anogenital distance was measured using a digital Vernier calliper (Tresna ${ }^{\circledR}$ China) at PND 1 as described earlier ${ }^{26}$.

\section{v. Determination of crown-rump length}

The crown-rump length was evaluated on PND 4 as described by Archibong et al. ${ }^{27}$.

\section{vi. Time of ear and eye-openings}


The time of ear openings was evaluated on PNDs 7-21 by clapping and then monitor the pup for lateral deviation to the sound, while that of the eye-opening was also done at the same period by definitory blinking reflex of the eye when approached with a sensor, a ball of cotton wool as stated by Cole et al. ${ }^{28}$ with slight modification, using clapping and monitoring for lateral deviation of the head to sound and a ball of cotton wool, for ear and eye-openings, respectively.

\section{vii. Time of testicular descent}

The time of testicular descent of the F1 pups was recorded as the time the testes descended into the scrotal sac as earlier described ${ }^{26}$. The evaluation of this parameter commenced on PND 16.

\section{Data Analysis}

The data obtained were expressed as mean \pm standard error of the mean (SEM) and subjected to oneway analysis of variance (ANOVA), followed by Tukey's post-hoc test to determine the significance of the differences in the mean values obtained between various experimental groups. The graphs were plotted using MS excel 2013 software after the data analysis with GraphPad Prism version 4 for windows. Values of $\mathrm{P} \leq 0.05$ were considered significant.

\section{Results}

\section{Effect of treatments on litter size in $\mathrm{F}_{1}$ generation male Wistar rats}

Figure 1. Effect of gestational and lactational exposure to Distilled water (DW), Soya oil (SO), Melatonin $(\mathrm{ML})$, Chlorpyriphos and Cypermethrin (CC), Melatonin + chlorpyriphos + cypermethrin (MC) and Chlorpyriphos + Cypermethrin $+\mathrm{ML}(\mathrm{CM})$ on litter size. $\mathrm{n}=10$. Values with different superscript differ significantly $(P<0.05)$. Results are expressed as \pm SEM.

\section{Effect of treatments on fetal live/dead ratio of $F_{1}$ generation male Wistar rats}

The fetal live/dead ratio in the CC group was significantly lower $(P<0.05)$, compared to that of the DW, SO and ML groups. There was a non-significant increase $(P>0.05)$ in the foetal live/dead ratio in the CC group when compared to that of the MC and CM groups (Figure 2).

\section{Effect of treatments on litter weight of $F_{1}$ generation male Wistar rats}

At PND 0,4,7,14 and 21, there was a significant $(P<0.05)$ decrease in the litter weight of the CC group relative to that of the DW, SO, ML, MC and CM groups. At PND 0,7,14 there was a significant $(P<0.05)$ decrease in the litter weight of the $C M$ group relative to that of $D W, S O$ and $M L$ groups, and a significant $(P<0.05)$ decrease in the litter weight of the ML group versus DW and SO groups (Figure 3 ). 
Effect of treatments on crown-rump length in $\mathrm{F}_{1}$ generation male Wistar rats

The crown-rump length in the CC group was significantly $(P<0.05)$ shorter, compared to that obtained in the DW, SO, ML, MC and CM groups. There was no significant $(P>0.05)$ change in the crown-rump length in the MC group when compared to that of the CM group (Figure 4).

\section{Effect of treatments on anogenital distance in $\mathrm{F}_{1}$ generation male Wistar rats}

There was no significant $(P>0.05)$ change in the anogenital distance between the groups. However, the anogenital distance in the CC group was shorter relative to that of the DW (17\%), SO (19\%), ML (15\%), MC (17\%) and CM (18\%) groups (Figure 5).

\section{Effect of treatments on the time of ear-opening of $F_{1}$ generation male Wistar rats}

The time of opening of the ear increased significantly $(P<0.05)$ in the CC group compared to that of DW, SO, ML, CM and MC groups. There was no significant $(P>0.05)$ change in the time of ear-opening in the $\mathrm{MC}$ group relative to that of the $\mathrm{CM}$ group (Figure 6).

\section{Effect of treatments on the time of eye-opening of $F_{1}$ generation male Wistar rats}

There was a significant $(P<0.05)$ increase in the time of eye-opening in the CC group compared to that of the DW, SO, ML, MC and CM groups. The time of eye-opening was significantly $(P<0.05)$ shorter in the DW group, relative to that of the MC and CM groups. Similarly, a significant $(P<0.05)$ decrease in the time of eye-opening was observed in the SO group relative to that of $\mathrm{ML}, \mathrm{MC}$ and $\mathrm{CM}$ groups. Also, the time of eye-opening in the ML group was significantly $(P<0.05)$ lower, relative to that of the $C M$ group (Figure 7).

\section{Effect of treatments on time of testicular descent of $F_{1}$ generation male Wistar rats}

Figure 8 shows the effect of treatments on the time of testicular descent. There was a significant $(\mathrm{P}<$ 0.05 ) increase in the time of testicular descent in the CC group compared to that of the DW group. Although not significant $(P>0.05)$, the time of testicular descent in the $\mathrm{CC}$ group relatively increased compared to that of the SO (16\%), ML (17\%), MC (17\%) and CM (16\%) groups.

\section{Discussion}

Exposure to neurotoxic chemicals during the developmental stages is a source of concern to the health and well-being of the developing organisms owing to the vulnerability of the central nervous system (CNS) during this period coupled with the immaturity of the brain-blood barrier ${ }^{29}$. The present study revealed alterations in the various developmental parameters in F1 male rats following gestational and lactational exposure to $\mathrm{CP}$ and $\mathrm{CY}$. 
The litter size is an important indicator of developmental and reproductive failure or success. In the present study, the mean litter size significantly decreased in the group exposed to the insecticide mixture compared to that of the other groups. This agrees with findings from previous studies on $\mathrm{CP}^{30,31}$ and $\mathrm{CY}^{32}$ in rats. The decrease in litter size has been documented as one of the foetotoxic signs of pesticide exposure and is attributed to several factors, including the ability of CP and CY to cross the placenta barrier ${ }^{33,34}$. Besides, previous studies have shown that $\mathrm{CP}^{30}$ and $\mathrm{CY}^{32}$ promote pre-implantation losses, which may affect litter size. Furthermore, oxidative injury to the fallopian tubes ${ }^{35}$ by the pesticide mixture may have created an unfavourable medium for implantation of the blastocysts, thereby resulting in lower litter size ${ }^{36}$. Increased apoptotic damage to the embryo observed with exposure to certain pesticides, including CP during the pre-implantation and post-implantation period ${ }^{37}$ may have contributed to the decrease in litter size in the group exposed to the pesticide mixture only. However, pre-and post-treatment with $\mathrm{ML}$ improved the litter size in the F1 male rats exposed to the pesticide mixture, partly due to its antioxidant properties. Melatonin acts as a direct ROS scavenge ${ }^{38}$ and as an indirect antioxidant by stimulating the synthesis and release of antioxidant enzymes ${ }^{39}$.

The present study has also revealed a significant decrease in the viability of pups from dams co-exposed to $\mathrm{CP}$ and $\mathrm{CY}$, as a greater number (22\%) of the pups in the $\mathrm{CC}$ group died. Cypermethrin has been found to induce DNA damage ${ }^{40}$, chromosomal aberrations ${ }^{41}$ and steroid hormone disruptions ${ }^{42}$. Indeed, $\mathrm{Madu}^{43}$ demonstrated a decrease in the number of live-born fetuses following $\mathrm{CY}$ exposure. Similarly, CP has also been shown to cause genotoxic effects through DNA damage and cell apoptosis ${ }^{40,44}$. The improvement in live/dead ratio following pretreatment or posttreatment with $M L$ suggests that the antioxidant agent counteracted the pesticide-induced toxicity possibly by protecting against ROS-induced DNA damage and protein oxidation ${ }^{45}$ coupled with its ability to decrease the level of certain pro-apoptotic enzymes like caspases 3 and $9^{46}$ and its ability to protects against genotoxic damages ${ }^{47}$, which eventually reduced prenatal and neonatal mortality.

The litter weight has been widely used as an indicator of foetotoxicity of a test substance ${ }^{48}$. The result of the present study showed a decrease in the litter weight of the F1 male generation of the CC group throughout the lactation period, relative to that of the other groups. This result agreed with previous findings following $\mathrm{CP}^{30}$ and $\mathrm{CY}^{43}$ exposure. Perera et al. ${ }^{13}$ reported an association between $\mathrm{CP}$ exposure and low-birthweight among the African-American population, while a similar relationship has been between umbilical cord plasma CP levels and foetal birth weight. The relative decrease in the pattern of weight changes in the groups co-exposed to the two pesticides may be partly due to cholinergic and oxidative stress, engendered by the pesticides ${ }^{49,50}$.

Pre-treatment and post-treatment with $M L$ showed a significant increase in litter weight relative to that of the CC group right from PND 0 to PND 21. Apart from expressing ML receptors in the placenta, melatonin has been shown to protect against oxidative damage induced in the rat placenta. Maternal treatment with $\mathrm{ML}$ in the present study may have improved placental efficiency, which therefore aids in the restoration of litter weight, partly due to an increase in the expression of placental Mn-SOD and catalase by the up- 
regulation of the placental antioxidant enzymes ${ }^{51}$. Furthermore, ML has been shown to improve blood and nutrient supply to developing foetus through improvement in uterine blood perfusion ${ }^{52}$.

The crown-rump length $(\mathrm{CRL})$ is a measure of fetal growth rate and has been used to evaluate growth retardation in response to the intrauterine exposure of the foetus to a noxious environmental chemical substance ${ }^{53}$. The present study showed a decrease in the mean CRL of F1 male generation rats in a group co-exposed to the pesticide mixture, indicating decreased foetal growth rate. This finding agrees with previous reports following gestational exposure to $\mathrm{CP}^{30,31}$ and $\mathrm{CY}^{53}$. The growth retardation in the newborn in the present study may be due to the ability of CP to concentrate in the milk. A concentrated form of $\mathrm{CP}$ residue has been demonstrated in the breast milk of mothers ${ }^{54}$ exposed to the pesticide, as it interacts with milk protein ${ }^{55}$, thereby posing a lot of danger to the newborn. Similarly, OP compounds also alter the activity of the milk lipase enzyme, resulting in diminished secretory function of the mammary gland, resulting in interference with the nursing of the offsprings ${ }^{56,57}$. In addition, CP easily crosses the placenta barrier ${ }^{58}$ causing direct cytotoxicity to the developing foetuses, thus impairing their growth and well-being. Furthermore, the pesticide mixture's ability to induce oxidative stress and other forms of stress may have created an unfavourable uterine environment for foetal growth and development, culminating in a reduction in CRL.

Pre-treatment and post-treatment with $\mathrm{ML}$ in the present study caused a significant increase in CRL, indicating an improvement in the foetal growth and a decrease in foetotoxicity, apparently due to its antioxidant property. Melatonin, up-regulates the activity of various antioxidant enzymes, while also enhancing the action of other antioxidants, such as ascorbate and tocopherol ${ }^{59}$. Through its mitigation of oxidative and cholinergic stress ${ }^{60,61}, \mathrm{ML}$ may have provided a better intrauterine environment necessary for foetal growth, in addition to reducing cytotoxicity induced by the pesticide mixture.

Anogenital distance (AGD), which has been used to gauge reproductive toxicities is a sexually dimorphic measure of genital development and a marker of endocrine disruption in animals and humans ${ }^{62}$. The AGD is dependent on prenatal exposure to androgens, which stimulate the growth of the perineum ${ }^{63}$. Although not significant, AGD in the F1 generation of male rats exposed to the pesticide mixture in the present study was relatively shorter than any of the other groups, including groups treated with $\mathrm{ML}$. This result suggests that the two pesticides have some degree of anti-androgenic effect on the foetuses, in agreement with findings from a previous study that reported low AGD following CP exposure ${ }^{30}$. Similarly, $\mathrm{CY}$ exerted anti-androgenic effects in androgen receptor gene assays ${ }^{64}$.

The restoration of the insecticide-induced deficit in AGD of F1 male rats in ML pre- and post-treated groups suggests its ability to ameliorate this developmental disorder. This could be partly attributed to the ability of ML to protect the Leydig cells of the developing foetus from insecticide-induced oxidative damage ${ }^{65}$, thereby retaining its capacity to produce testosterone during the stage critical to foetal urogenital development. 
The present study recorded a slight delay in the time of the ear opening. This agrees with the finding of previous studies following gestational exposure to $\mathrm{CP}^{66}$ and $\mathrm{CY}^{67}$ in rats. Stimuli from the skeletal muscles, which have been reported to play a role in the foetal development of the external ear, may have also been partly responsible for the delay in the time of opening of the ear in the present study. Melatonin was able to normalise the time of pinna opening, possibly by reducing both the maternal and foetal toxicity, engendered by the pesticides possibly by its antioxidant properties.

The significant delay in the time of eye-opening in $\mathrm{F} 1$ generation from dams in the $\mathrm{CC}$ group indicates that the insecticide combination impaired this important developmental landmark. Several studies have demonstrated the ability of $C Y$ to cause delay of eye-opening in rats ${ }^{67,68}$. The delay in eye-opening may be partly due to retarded synaptogenesis of the primary visual cortex $(\mathrm{VI})^{69}$, possibly due to oxidative stress provoked by the insecticide mixture. Oxidative stress plays an important role in synaptogenesis through the activation of mitogen protein activated kinase (MAPK) signalling pathways ${ }^{70}$.

Pretreatment with melatonin was able to reduce the time of eye-opening, possibly due to the mitigation of oxidative stress evoked by the insecticide mixture, which allows the normal process of synaptogenesis of the primary visual cortex $(\mathrm{VI})$. Melatonin may also have reduced the activation of the MAPK signalling pathway since antioxidants have been shown to reduce the activation of p38 MAPK ${ }^{71}$. The implication of improved synaptogenesis by melatonin possibly due to the reduction of oxidative stress is early maturation of the visual cortex, which resulted in the reduction in the time of eye-opening.

Undescended testicles are the most common congenital birth defect in male children and were generally accepted to affect $2-4 \%$ of baby boys ${ }^{72}$. In the present study, there was an increase in the time of testicular descent in the group exposed to pesticide mixture only, which indicates changes in the physical parameter of sexual maturation ${ }^{73}$. Testicular descent is testosterone dependent, hence a decrease in testosterone concentration, which has been documented to be engendered by $\mathrm{CP}^{74}$ and $\mathrm{CY}^{75}$ may have been partly responsible for the infraction on this developmental parameter. The improvement in the time of testicular descent in the FI generation from dams pretreated with melatonin may be due to its widely proven antioxidant effect, which may have protected vital reproductive endocrine organs/cell such as the hypothalamus, pituitary gland and the Leydig cells, thus, allowing them to regulate the synthesis and secretion of androgens. A previous study has shown the ability of $M L$ to mitigate CP-evoked disruption of the pituitary-gonadal axis ${ }^{76}$.

Although the present study did not evaluate the redox status of the animals under observation, it is however known that exposure to pesticides causes genetic and epigenetic modifications, endocrine disruption, mitochondrial dysfunction and oxidative stress ${ }^{77}$. Reactive oxygen and nitrogen species play some roles in regulating essential cellular signalling pathways such as cell differentiation, proliferation, migration and apoptosis ${ }^{78}$. This may have been partly responsible for the developmental toxicity caused by the pesticide mixture in the present study. The mitigation by melatonin may also have been partly due to its antioxidant effect through direct and indirect pathways. The direct antioxidant and free radical 
scavenging properties of melatonin are mainly due to its electron-rich aromatic indole ring, which makes it a potent electron donor that can significantly reduce oxidative stress ${ }^{79,80}$. Indirectly, melatonin does activate melatonin (MT) 1 and MT2 receptors and upregulate antioxidative defensive systems by increasing the expression or activity of antioxidant enzymes such as superoxide dismutase and glutathione peroxidase ${ }^{81}$. Apart from its antioxidant effect, the ability of melatonin to mitigate the toxic effect arising from in utero exposure to mixture $\mathrm{CP}$ and $\mathrm{CY}$ in $\mathrm{F} 1$ generation may be due to its antiapoptotic effect. Melatonin has been shown to modulate the $\mathrm{Bcl}-2$ protein expression, blocks Bax proapoptotic activity via the SIRT1/NF-kB axis with a consequent and significant inhibition of Cytochrome $\mathrm{C}$ release and the lack of apoptosome formation and caspase 3 activations ${ }^{82,83}$.

In conclusion, the present study has demonstrated that gestational and lactational co-exposure to $\mathrm{CP}$ and $\mathrm{CY}$ alter some developmental landmarks in the resulting male F1 generation, which may adversely affect their future developmental and reproductive potentials. Melatonin, when given before gestational and lactational exposure to insecticides or even after their exposure, acting both as a prophylactic and curative agent mitigated the developmental alterations in the F1 generation.

\section{Declarations}

\section{Ethical approval}

Ethical approval was obtained from the Ahmadu Bello University Committee on Animal Use and Care (Ethical Approval no: ABUCAUC/2020/002).

\section{Consent to participate}

Not applicable

\section{Consent to publish}

Not applicable

\section{Authors Contributions}

Shittu Muftau (SM) was responsible for project administration, performed the experiments and analysed the data; Suleiman Folorunsho Ambali (SFA) was involved in project design and validation, Joseph Olusegun Ayo (JOA) and Mohammed Umaru Kawu (MUK) were involved in editing and validation; Akande Motunrayo Ganiyat (AMG) assisted with sample collection and data analysis. The manuscript was drafted by SM, SFA, JOA and MUK and approved by all authors.

\section{Funding}

The authors received no funding for the research.

\section{Competing Interests}


The authors declare they have no competing interests.

\section{Availability of data and materials}

All data generated and analysed during this study are included as a supplementary information file.

\section{References}

1. Abdou RH, Elbadawy M, Khalil WF et al (2020) Effects of several organophosphates on hepatic cytochrome P450 activities in rats. J Vet Med Sci 82(5): 598-606. doi: 10.1292/jvms.19-0452.

2. Taiwo AM (2019) A review of environmental and health effects of organochlorines pesticide residues in Africa. Chemosphere 220: 1126-1140. https://doi.org/10.1016/j.chemosphere.2019.01.001.

3. Doss C, Meinzen-Dick R, Quisumbing A et al (2018) Women in agriculture: four myths. Glob Food Sec 16: 69-74. doi: 10.1016/j.gfs.2017.10.001.

4. Alipour V, Hoseinour F, Vatanparast $J$ et al (2019) Persistent alterations in seizure susceptibility, drug responsiveness and comorbidities associated with chemical kindling after neonatal exposure to an organophosphate. NeuroToxicol 73: 92-99. https://doi.org/10.1016/j.neuro.2019.03.002.

5. Doherty BT, Hoffman K, Keil AP et al (2019) Prenatal exposure to organophosphate esters and cognitive development in young children in the pregnancy, infection and nutrition study. Environ Res 169: 33-40. doi: 10.1016/j.envres.2018.10.033.

6. Kung S, Richardson JR, Coope KR et al (2015) Developmental deltamethrin exposure causes persistent changes in dopaminergic gene expression, neurochemistry, and locomotor activity in Zebrafish Tiffany. Toxicol Sci 146(2): 235-243. doi: 10.1093/toxsci/kfv087.

7. Idris SB, Ambali SF, Mohammed B et al (2014) Effects of melatonin on changes in cognitive performances and brain malondialdehyde concentration induced by sub-chronic co-administration of chlorpyrifos and cypermethrin in male Wister rats. Asian Pac J Trop Biomed 4(4): 318-323. doi: 10.12980/APJTB.4.2014C55.

8. Steenland K, Dich RB, Howell RJ et al (2000) Neurologic function among termiticide applicators exposed to chlorpyrifos. Environ Health Perspect 108 (4): 293-300. doi: 10.1289/ehp.00108293.

9. Abdel-Daim M, Dawood MAO, Elbadawy M et al (2020) Spirulina platensis reduced oxidative damage induced by chlorpyrifos toxicity in Nile Tilapia (Oreochromis niloticus). Animals 10(3): 473. doi:10.3390/ani10030473.

10. Abdel-Rahman A, Blumenthal G, Abou-Donia S et al (2002) Pharmacokinetic profile and placental transfer of a single intravenous injection of [14C] chlorpyrifos in pregnant rats. Arch Toxicol 76: 452459. DOI: 10.1007/s00204-002-0366-2 
11. Burke RD, Todd SW, Lumsden E et al (2017) Developmental neurotoxicity of the organophosphorous insecticide chlorpyrifos: from clinical findings to preclinical models and potential mechanisms. J. Neurochem 142(2): 162-177. doi: 10.1111/jnc.14077.

12. Farag AT, El Okazy AM, El-Aswed AF (2003) Developmental toxicity study of chlorpyrifos in rats. Reprod Toxicol 17: 203-208. doi.org/10.1016/S0890-6238(02)00121-1.

13. Perera FP, Rauh V, Tsai W-Y et al (2003) Effects of transplacental exposure to environmental pollutants on birth outcomes in a multiethnic population. Environ Health Perspect 111(2): 201-205. doi: 10.1289/ehp.5742.

14. Siqueira AA, Cunha AF, Marques GLM et al (2019) Atropine counteracts the depressive-like behaviour elicited by acute exposure to commercial chlorpyrifos in rats. Neurotoxicol Teratol 71: 6-15. DOI:10.1016/j.ntt.2018.11.002.

15. Yavasoglu A, Sayin F, Uyanikgli Y, Turgut M, Karabay-Yavasoglu NU (2006) The pyrethroids cypermethrin-induced biochemical and histological alterations in rats liver. J Health Sci 52(6): 774780. DOI: $10.1248 /$ jhs. 52.774 .

16. Joshi SC, Bansal B, Jasuja ND (2011) Evaluation of reproductive and developmental toxicity of cypermethrin in male albino rats. Toxicol Environ Chem 93(3): 593-602. DOI: $10.1080 / 02772248.2010 .537441$.

17. Shi X, Gu A, Ji G, et al (2011) Developmental toxicity of cypermethrin in embryo larval stages of zebrafish. Chemosphere 85(6): 1010-1016. https://doi.org/10.1016/j.chemosphere.2011.07.024.

18. Reiter RJ, Tan D, Fuentes-Broto L (2010) Melatonin: a multitasking molecule. Prog Brain Res. 181(08): 127-151. https://doi.org/10.1016/S0079-6123(08)81008-4.

19. Lekic T, Hartman R, Rojab H et al (2010) Protective effect of melatonin upon neuropathology, striatal function and memory ability after intracerebral haemorrhage in rats. J Neurotrauma 27(3): 627-637. doi: 10.1089/neu.2009.1163.

20. Lanoix D, Lacasse A-A, Reiter RJ et al (2012) Melatonin: the smart killer. The human trophoblast as a model. Mol Cell Endocrinol 348: 1-11. doi: 10.1016/j.mce.2011.08.025.

21. Samir H, Nyametease P, Elbadawy M, et al (2020) Administration of melatonin improves testicular blood flow, circulating hormones, and semen quality in Shiba goats. Theriogenology 146: 111-119. doi: 10.1016/j.theriogenology.2020.01.053.

22. Kilkenny C, Brown WJ, Cuthil IC, Emerson M, Altman DG (2010) Improving Bioscience Research Reporting: The ARRIVE Guidelines for Reporting Animal Research. PLoS Biol 8(6): e1000412. Doi.org/10.1371/journal.pbio.1000412. 
23. Organisation for Economic Co-operation and Development (No. 421) (2016). Reproduction /developmental toxicity screening test. Available from https://doi.org/10.1787/9789264264380-en.

24. Shittu M, Ambali SF, Ayo JO et al (2021) Melatonin mitigates thyroid dysfunction induced by gestational and lactational exposure to mixture of chlorpyrifos and cypermethrin in male Wistar rats. Comp Clin Path 30: 529-540. doi.org/10.1007/s00580-021-03247-8.

25. Breslin WJ, Liberacki AB, Dittenber DA et al (1996) Evaluation of the developmental and reproductive toxicity of chlorpyrifos in the rat. Fund Appl Toxicol 29(13):119-130. doi: 10.1006/faat.1996.0013.

26. Schwartz CL, Christiansen S, Vinggaard AM et al (2019) Anogenital distance as a toxicological or clinical marker of fetal androgen action and risk for reproductive disorders. Arch Toxicol 93: 253-272. doi: 10.1007/s00204-018-2350-5.

27. Archibong AE, Inyang F, Ramesh A et al (2002) Alteration of pregnancy related hormones and foetal survival in F-344 rats exposed by inhalation to benzo(a)pyrene. Reprod Toxicol 16(2): 801-808. DOI:10.1016/S0890-6238(02)00058-8.

28. Cole TB, Fisher JC, Burbacher TM et al (2012) Neurobehavioural assessment of mice following repeated postnatal exposure to chlorpyrifos oxon. Neurotoxicol Teratol 34(3): 311-322. DOI: 10.1016.j.ntt.2012.02.003.

29. Lee J, Freeman JL (2014) Zebrafish as a model for developmental neurotoxicity assessment: The application of the Zebrafish in defining the effects of Arsenic, methylmercury or lead on early neurodevelopment. Toxics 2: 464-495. https://doi.org/10.3390/toxics2030464.

30. Ambali SF, Abbas SO, Shittu M et al (2009) Effects of gestational exposure to chlorpyrifos on implantation and neonatal mice. J Cell Anim Biol 3(4): 050-057. https://doi.org/10.5897/JCAB.9000062.

31. Shalaby MA, Abo-El-Sooud K, Hamoda AA (2013) Assessment of toxicity of chlorpyrifos insecticide on fetuses and suckling pups of rats. Insight Ecology 2(1): 1-7. DOI: 10.5567/ECOLOGY-IK.2013.1.7.

32. Assayed ME, Khalaf AA, Salem HA (2010) Protective effects of garlic extract and vitamin C against in vivo cypermethrin-induced teratogenic effects in rat offspring. Food Chem Toxicol 48: 3153-3158. DOI: 10.1016/j.fct.2010.08.011.

33. Dewailly E, Forde M, Robertson L et al (2014) Evaluation of pyrethroid exposures in pregnant women from 10 Caribbean countries. Environ Int 63: 201-206. doi: 10.1016/j.envint.2013.11.014.

34. Rager JE, Bangma J, Carberry C et al (2020) Review of the environmental prenatal exposome and its relationship to maternal and fetal health. Reprod Toxicol, 98: 1-12. doi.org/10.1016/j.reprotox.2020.02.004. 
35. Guney M, Oral B, Demirin H et al (2007) Fallopian damage induced by organophosphate insecticide methyl parathion, and protective effect of vitamins $E$ and $C$ on ultrastructural changes in rats. Toxicol Ind Health 23: 429-438. doi: 10.1177/0748233707076773.

36. Talbot $\mathrm{P}$, Riveles $\mathrm{K}$ (2005) Smoking and reproduction: the oviduct as a target of cigarette smoke. Reprod Biol Endocrinol 3: 52. DOI. 10.1186/14777827-3-52.

37. Rezvanfar MA, Hodjat M, Abdollahi M (2016) Growing knowledge of using embryonic stem cells as a novel tool in developmental risk assessment of environmental toxicants. Life Sci 158: 137-160. doi: 10.1016/j.Ifs.2016.05.027.

38. Mihandoost E, Shirazi A, Mahdavi SR et al (2014) Can melatonin help us in radiation oncology treatments? Review. BioMed Res Int doi,http://dx.doi.org/10.1155/2014/578137.

39. Rodriguez C, Mayo JC, Sainz RM et al (2004) Regulation of antioxidant enzymes: a significant role for melatonin. J Pineal Res 36: 1-9. doi: 10.1046/j.1600-079x.2003.00092.x.

40. Hocine L, Merzouk H, Merzouk SA et al (2016) The effects of alpha-cypermethrin exposure on biochemical and redox parameters in pregnant rats and their newborns.Pestic Biochem Phys 134: 49-54. doi: 10.1016/j.pestbp.2016.04.007.

41. Huang F, Liu Q, Xie S et al. (2016) Cypermethrin induces macrophages death through cell cycle arrest and oxidatice stress-mediated JNK/ERK signaling regulated apoptosis. Int J Mol Sci 17.885. DOI: $10.3390 / \mathrm{ijms} 17060885$.

42. Campos E, Freire, C (2016) Exposure to non-persistent pesticides and thyroid function: A systematic review of epidemiological evidence. Int J Hyg Environ Health 219(6): 481-497. DOI: 10.1016/j.jhheh.2016.05.006.

43. Madu EP (2015) Teratogenic and embryotoxic effect of orally administered cypermethrin in pregnant albino rats. J Toxicol Environ Health Sci 7(7): 60-67. DOI: 10.5897/JTEHS2015.0336.

44. Vardavas Al, Stivaktakis PD, Tzatzarakis MN et al (2016) Long-term exposure to cypermethrin and piperonyl butoxide cause liver and kidney inflammation and induce genotoxicity in New Zealand white male rabbits. Food Chem Toxicol 94: 250-259. doi: 10.1016/j.fct.2016.06.016.

45. Ghayomi F, Navaei-Nigjeh M, Baeeri M et al (2015) A mechanistic approach for modulation of chlorpyrifos-induced toxicity in human lymphocytes by melatonin, coenzyme Q10, and vinpocetine. Hum Exp Toxicol 35(8): 839-850. doi: 10.1177/0960327115607945.

46. Espino J, Ortiz A, Bejarano I et al (2011) Melatonin protects human spermatozoa from apoptosis via melatonin receptor and extracellular signal regulated kinase-mediated pathways. Fertil Steril 95(7): 2290-2296. doi: 10.1016/j.fertnstert.2011.03.063. 
47. do Nascimento Marinho KS, Lapa Neto CJC, de Sousa Coelho IDD et al (2019) Genotoxic and mutagenic evaluation of the protective effect of exogenous melatonin in adult rats and their offspring exposed to the insecticides methomyl and cypermethrin during pregnancy. Mutat Res 848:503107. doi:10.1016/j.mrgentox.2019.503107.

48. El-Baz MAH, El-Deek SEM, Nsar AY et al (2015) Prenatal pesticide exposure: meconium as a biomarker and impact on fetal weight. J Environ Anal Toxicol 5:

49. DOI: $10.4172 / 2161-0525.1000268$.

49. Ikpeme EV, Okonko LE, Udensi OU (2016) Detrimental effects of chlorpyrifos and cypermethrin on reproductive physiology of male albino rats. Res J Environ Toxicol 10 (1): 68-74. DOI: 10.3923/rjet.2016.68.74.

50. Felippe ISA, Muller CJT, Siqueira AA et al (2020) The antidotes atropine and pralidoxime distinctively recover cardiorespiratory components impaired by acute poisoning with chlorpyrifos in rats. Toxicology and Applied Pharmacology 389: doi.org/10.1016/j.taap.2020.114879.

51. Richter HG, Hansell JA, Raut S et al (2009) Melatonin improves Placental efficiency and birth weight and increases the placenta expression of antioxidant enzymes in undernourished pregnancy. $J$ Pineal Res 46(4): 357-364. doi: 10.1111/j.1600-079X.2009.00671.x.

52. Lemley, CO, Meyer, AM, Camacho LE et al (2012) Melatonin supplementation alters uteroplacental hemodynamics and fetal development in an ovine model of intrauterine growth restriction. Am J Physiol Regul Integr Comp Physiol 302(4): R454-R467. doi: 10.1152/ajpregu.00407.2011.

53. Raees K, Asmatullah, Ahmad KR (2010) Pregnancy and fetal correlations of cypermethrin in mice (Mus musculus). Biologia (Pakistan) 56 (1and2): 39-54.

54. Brahmand MB, Yunesian M, Nabizadeh R et al (2019) Evaluation of chlorpyrifos residue in breast milk and its metabolite in urine of mothers and their infants feeding exclusively by breast milk in North of Iran. J Environ Health Sci Eng 17: 817-825. DOI: 10.1007/s40201-019-00398-3.

55. Lv Y, Li X, Wang X et al (2014) Interaction of bovine milk protein with chlorpyrifos. J Dairy Sci 97: 2056-2060. doi: 10.3168/jds.2013-7581.

56. Mansour SA, Mossa AH (2010) Adverse effects of lactational exposure to chlorpyrifos in suckling rats. Hum Exp Toxicol 29(2): 77-92. doi: 10.1177/0960327109357276.

57. O'Sullivan A, Farver M, Smilowitz JT (2015) The influence of early infant-feeding practices on the intestinal microbiome and body composition in infants. Nutri Metab Insights 8(Suppl 1): 1-9. doi: 10.4137/NMI.S29530. 
58. Koutroulakis D, Sifakis S, Tzatzarakis MN et al (2014) Dialkyl phosphates in amniotic fluid as a biomarker of fetal exposure to organophosphates in Crete, Greece; association with fetal growth. Reprod Toxicol 46:98-105. https://doi.org/10.1016/j.reprotox.2014.03.010.

59. Hardeland R1, Pandi-Perumal SR (2005) Melatonin, a potent agent in antioxidative defense: actions as a natural food constituent, gastrointestinal factor, drug and prodrug. Nutr Metab 2: 22. DOI: 10.1186/1743-7075-2-22.

60. Buyukokuroglu ME, Cemek M, Yurumez Y (2008) Antioxidantive role of melatonin in organophosphate toxicity in rats. Cell Biol Toxicol 24(2): 151-158. DOI: 10.1007/s10565-007-9024-z.

61. Reiter RJ, Tan D-X, Manchester LC et al (2009) Melatonin and reproduction revisited. Biol Reprod 81(3):445-456. doi: 10.1095/biolreprod.108.075655.

62. Liu C, Xu X, Huo X (2014) Anogenital distance and its application in environmental health research. Environ Sci Pollut Res Int 21(8): 5457-5464. doi: 10.1007/s11356-014-2570-z.

63. Ostby JS, Gray LEJr (2004) Transgenerational (in utero/lactational) exposure to investigate the effects of endocrine-disrupting compounds (EDCS) in rats. Curr Protoc Toxicol Chapter 16: Unit 16.8. DOI: $10.1002 / 0471140856 . t \times 1608 s 19$.

64. Pan C, Wang Q, Liu Y-P et al (2013) Anti-androgen effects of the pyrethroid pesticide cypermethrin on interactions of androgen receptor with corepressors. Toxicol 311(3): 178-183. https://doi.org/10.1016/j.tox.2013.06.011.

65. Xu G, Zhao J, Liu H, Wang J, Lu W (2019) Melatonin inhibits apoptosis and oxidative stress of mouse Leydig cell via a SIRT 1-dependent mechanism. Molecules 24(1): 3084. DOI: 10.3390/molecules24173084.

66. Maurissen JP, Hoberman AM, Garman RH et al (2000) Lack of selective developmental neurotoxicity in rat pups from dams treated by gavage with chlorpyrifos. Toxicol Sci 57: 250-263. doi: 10.1093/toxsci/57.2.250.

67. Farag AT, Goda NF, Shaaban NA et al (2007) Effects of oral exposure of synthetic pyrethoid, cypermethrin on the behaviour of F1-progeny in mice. Reprod Toxicol 23: 560-567. doi: 10.1016/j.reprotox.2007.01.002.

68. Husain R, Malaviya M, Seth PK (1992) Differential responses of regional brain polyamines following in utero exposure to synthetic pyrethroids: A preliminary report. Bull. Environ. Contam. Toxicol. 49: 402-409. doi: 10.1007/BF01239644.

69. Ghandhi SP, Cang J, Stryker MP (2005) An eye-opening experience. Nat Neurosci 8(1): 9-10. doi: 10.1038/nn0105-9. 
70. Milton VJ, Sweeney ST (2012) Oxidative stress in synapse development and function. Dev Neurobiol 72(1): 100-110. doi: 10.1002/dneu.20957.

71. Gaitanaki C, Papatriantafyllou M, Konstantina S et al (2006) Effects of various oxidants and antioxidants on the p38-MAPK signaling pathway in the perfused amphibian heart. Mol Cell Biochem 291: 107-117. doi: 10.1007/s11010-006-9203-x.

72. Ferlin A, Zuccarello D, Zuccarello B et al (2008) Genetic alterations associated with cryptorchidism. J Am Med Assoc 300(19):2271-2276. doi: 10.1001/jama.2008.668.

73. Farkas J, Reglodi D, Gaszner B et al (2009) Effects of maternal separation on the neurobehavioral development of newborn Wistar rats. Brain Res Bull 79(3-4): 208-214. doi:

10.1016/j.brainresbull.2008.12.011.

74. Shittu M, Olatunji AO, Ambali SF et al (2014) Ameliorative effect of Hibiscus sabdariffa Linn on subchronic chlorpyrifos induced alterations in sex and theroid hormone in male Wistar rats. Am J Pharmacol Toxicol 9(1): 96-106.

75. Sharma P, Huq AU, Singh R (2014) Cypermethrin-induced reproductive toxicity in the rat is prevented by resveratrol. J Hum Reprod Sci 7(2): 99-106. doi: 10.4103/0974-1208.138867.

76. Umosen AJ, Chidiebere U (2014) Effect of melatonin on chlorpyrifos-induced alterations in reproductive hormones and semen characteristics in Wistar rats. Am J Phytomed Clin Ther 2: 742753.

77. Yusoff NA, Taib IS, Budin SB et al (2021) Paternal Fenitrothion exposures in rats causes sperm DNA fragmentation in $\mathrm{F} 0$ and histomorphometric changes in selected organs of $\mathrm{F} 1$ generation. Toxics 9: 159. https://doi.org/ 10.3390/toxics9070159

78. Ojha A, Srivastava N (2012) Redox imbalance in rats tissues exposed with organophosphates pesticides and therapeutic potential of antioxidant vitamins. Ecotox Environ Safe 75: 230-241. doi: 10.1016/j.ecoenv.2011.08.013.

79. Acuna-Castroviejo D, Escames G, Venegas $C$ et al (2014). Extrapineal melatonin: sources, regulation, and potential functions. Cell Mol Life Sci 71: 2997-3025. DOI: 10.1007/s00018-014-1579-2.

80. Tan DX., Manchester LC, Esteban-Zubero E et al (2015). Melatonin as a potent and inducible endogenous antioxidant: synthesis and metabolism. Molecules 20: 18886-18906. doi: 10.3390/molecules201018886.

81. Tomas-Zapico C and Coto-Montes A (2005). A proposed mechanism to explain the stimulatory effect of melatonin on antioxidative enzymes. J. Pineal Res. 39(2): 99-104. doi: 10.1111/j.1600079X.2005.00248.x. 
82. Sun FY, Lin X, Mao L et al. (2002). Neuroprotection by melatonin against ischemic neuronal injury associated with modulation of DNA damage and repair in the rat following a transient cerebral ischemia. J Pineal Res 33: 48-56. doi: 10.1034/j.1600-079x.2002.01891.x.

83. Tarocco A, Caroccia N, Morciano G et al. (2019) Melatonin as a master regulator of cell death and inflammation: molecular mechanisms and clinical implications for newborn care. Cell Death and Disease 10(4):317. doi: 10.1038/s41419-019-1556-7.

\section{Figures}

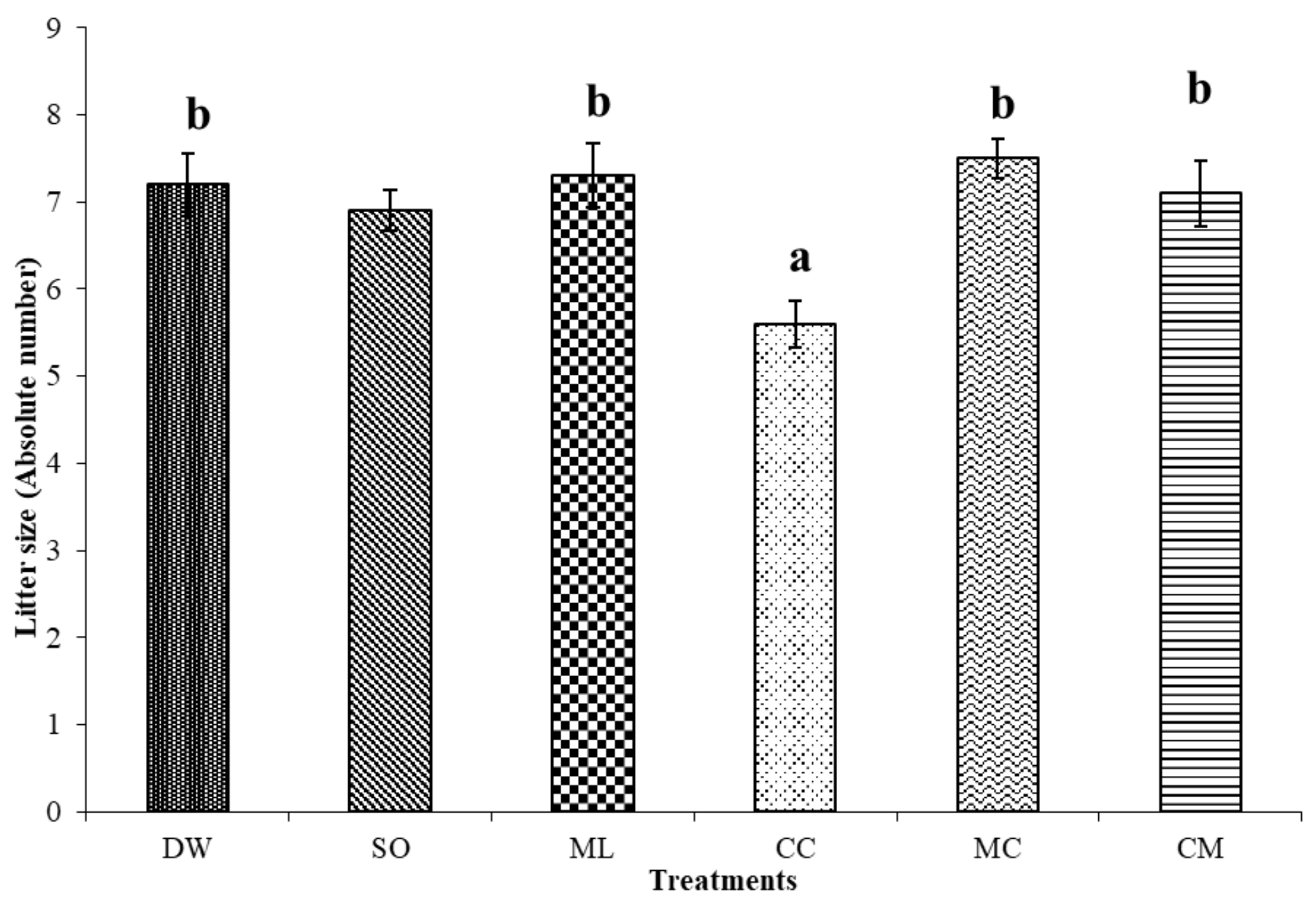

Figure 1

Effect of gestational and lactational exposure to Distilled water (DW), Soya oil (SO), Melatonin (ML), Chlorpyriphos and Cypermethrin (CC), Melatonin + chlorpyriphos + cypermethrin (MC) and Chlorpyriphos + Cypermethrin $+M L(C M)$ on litter size. $n=10$. Values with different superscript differ significantly $(P<$ $0.05)$. Results are expressed as \pm SEM. 


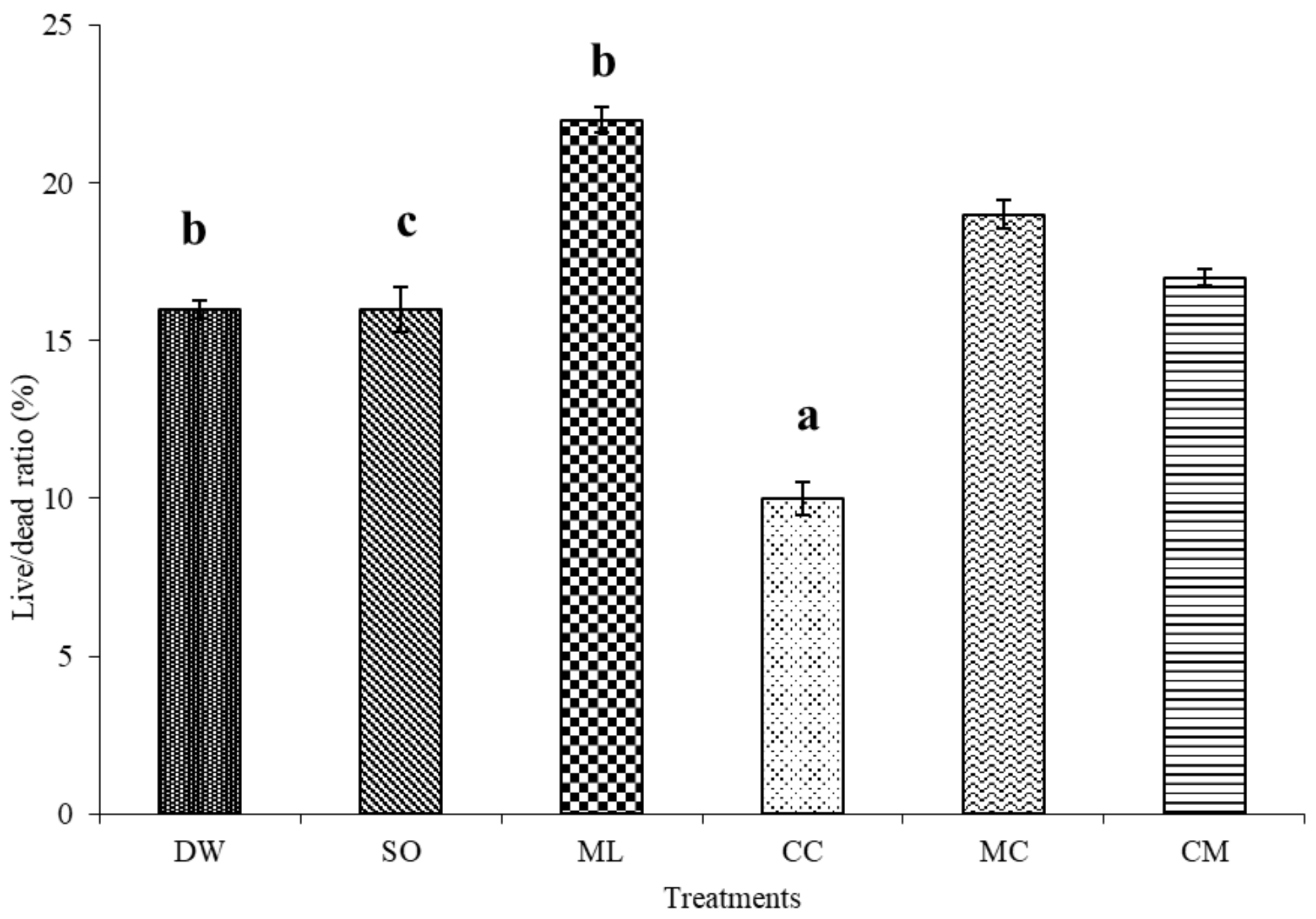

Figure 2

Effect of gestational and lactational exposure to Distilled water (DW), Soya oil (SO), Melatonin (ML), Chlorpyriphos and Cypermethrin (CC), Melatonin + chlorpyriphos + cypermethrin (MC) and Chlorpyriphos + Cypermethrin $+M L(C M)$ on fetal live/dead ratio. $n=10$. Bars with different superscript differ significantly $(P<0.05)$. Results are expressed as \pm SEM. 


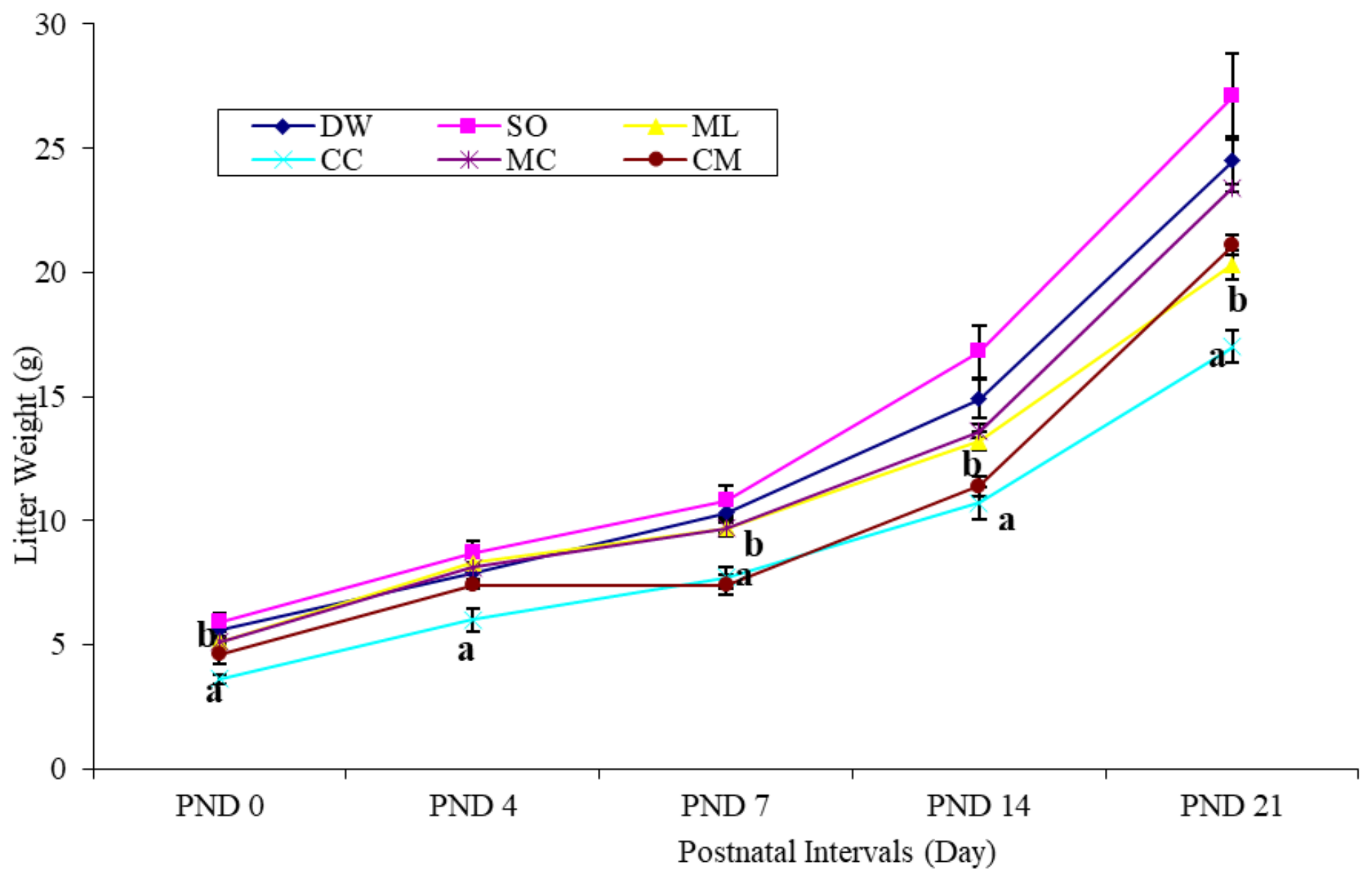

Figure 3

Effect of gestational and lactational exposure to Distilled water (DW), Soya oil (SO), Melatonin (ML), Chlorpyriphos and Cypermethrin (CC), Melatonin + chlorpyriphos + cypermethrin (MC) and Chlorpyriphos + Cypermethrin $+M L(C M)$ on dynamics of Litter weight $n=10$. Values with different superscript differ significantly $(P<0.05)$. Results are expressed as \pm SEM. 


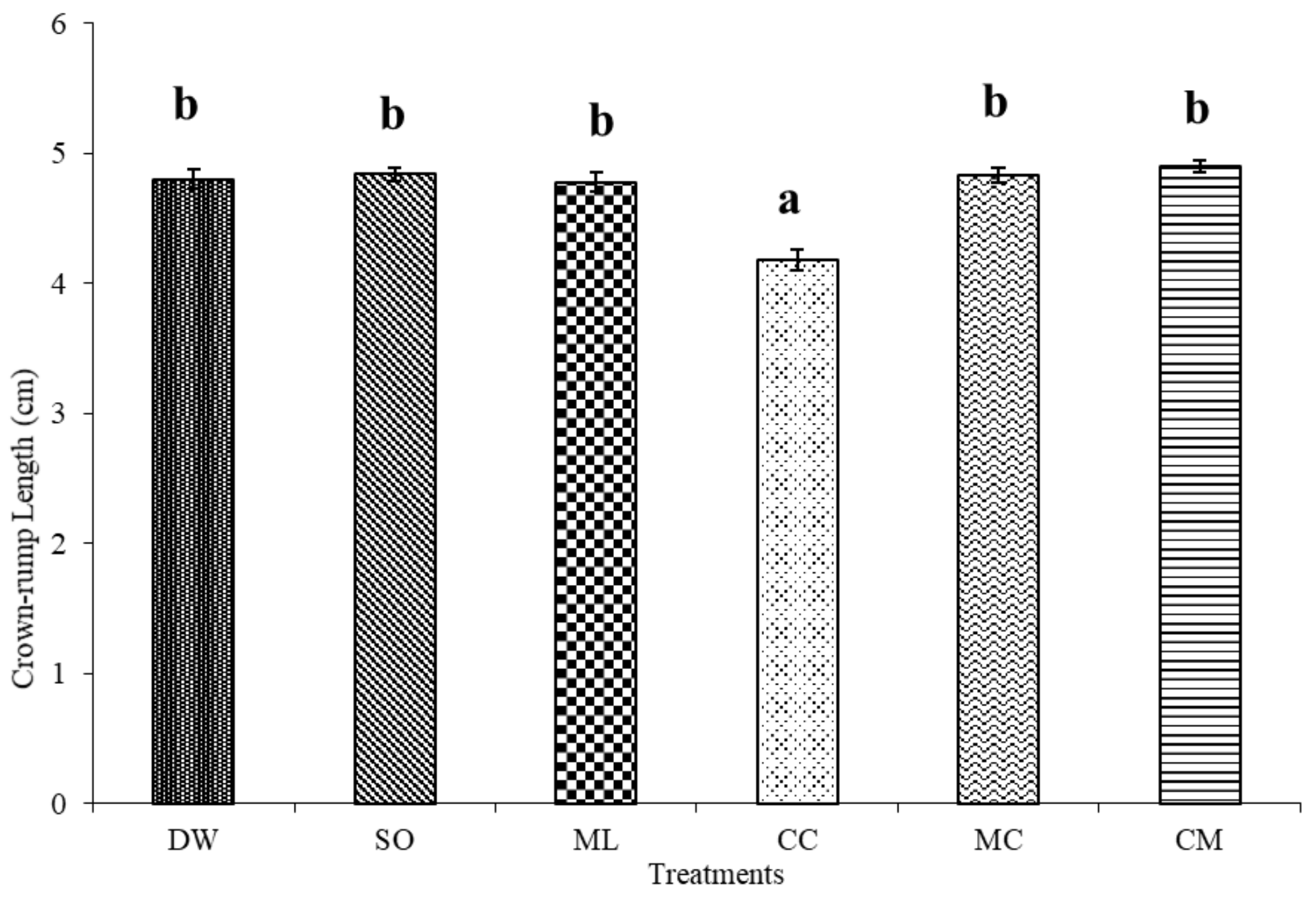

Figure 4

Effect of gestational and lactational exposure to Distilled water (DW), Soya oil SO), Melatonin (ML), Chlorpyriphos and Cypermethrin (CC), Melatonin + chlorpyriphos + cypermethrin (MC) and Chlorpyriphos + Cypermethrin $+M L(C M)$ on crown-rump length. $n=10$. Bars with different superscript differ significantly $(P<0.05)$. Results are expressed as \pm SEM. 


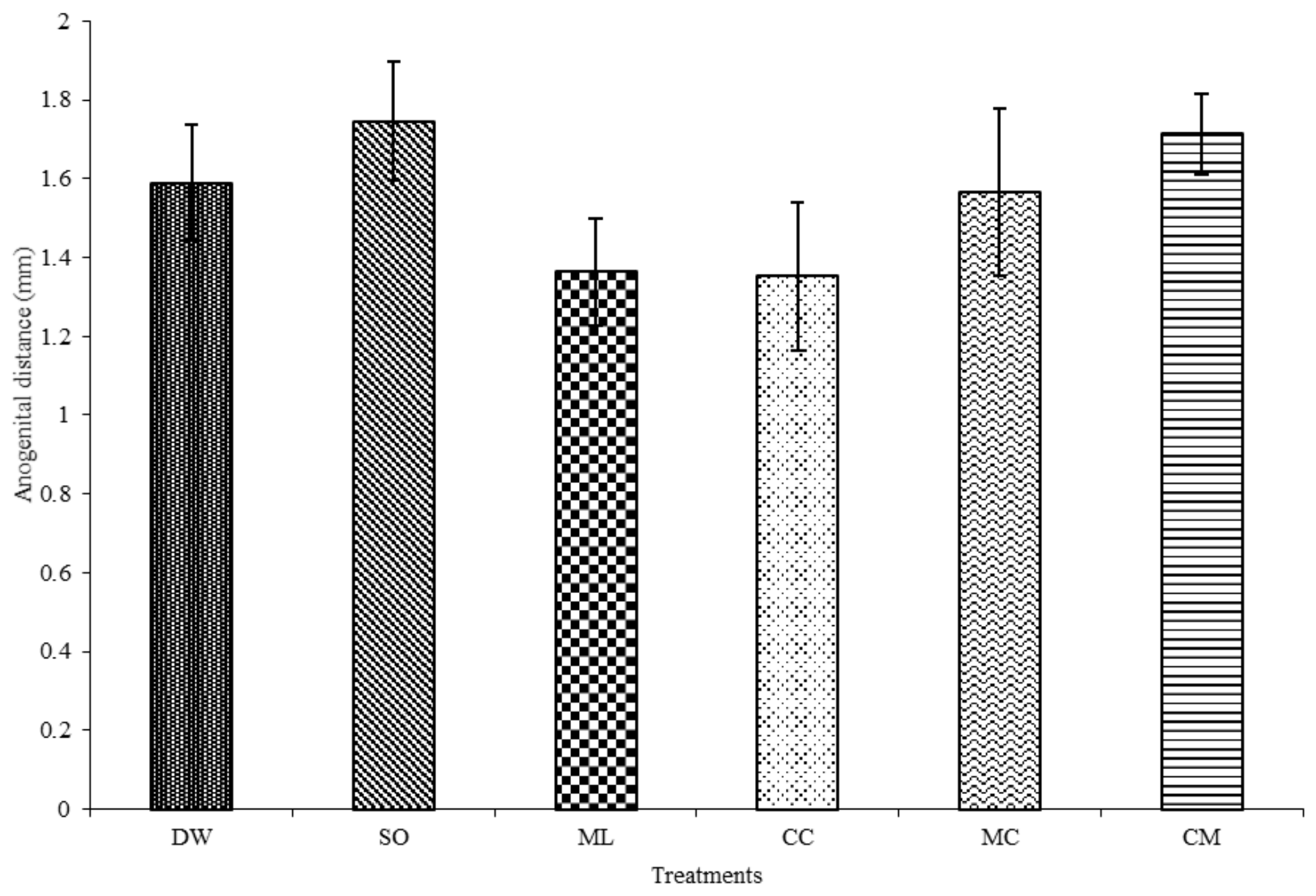

Figure 5

Effect of gestational and lactational exposure to Distilled water (DW), Soya oil (SO), Melatonin (ML), Chlorpyriphos and Cypermethrin (CC), Melatonin + chlorpyriphos + cypermethrin (MC) and Chlorpyriphos + Cypermethrin $+M L(C M)$ on anogenital distance $n=10$. Bars with same superscript are not statistically significant $(P>0.05)$. Results are expressed as \pm SEM. 


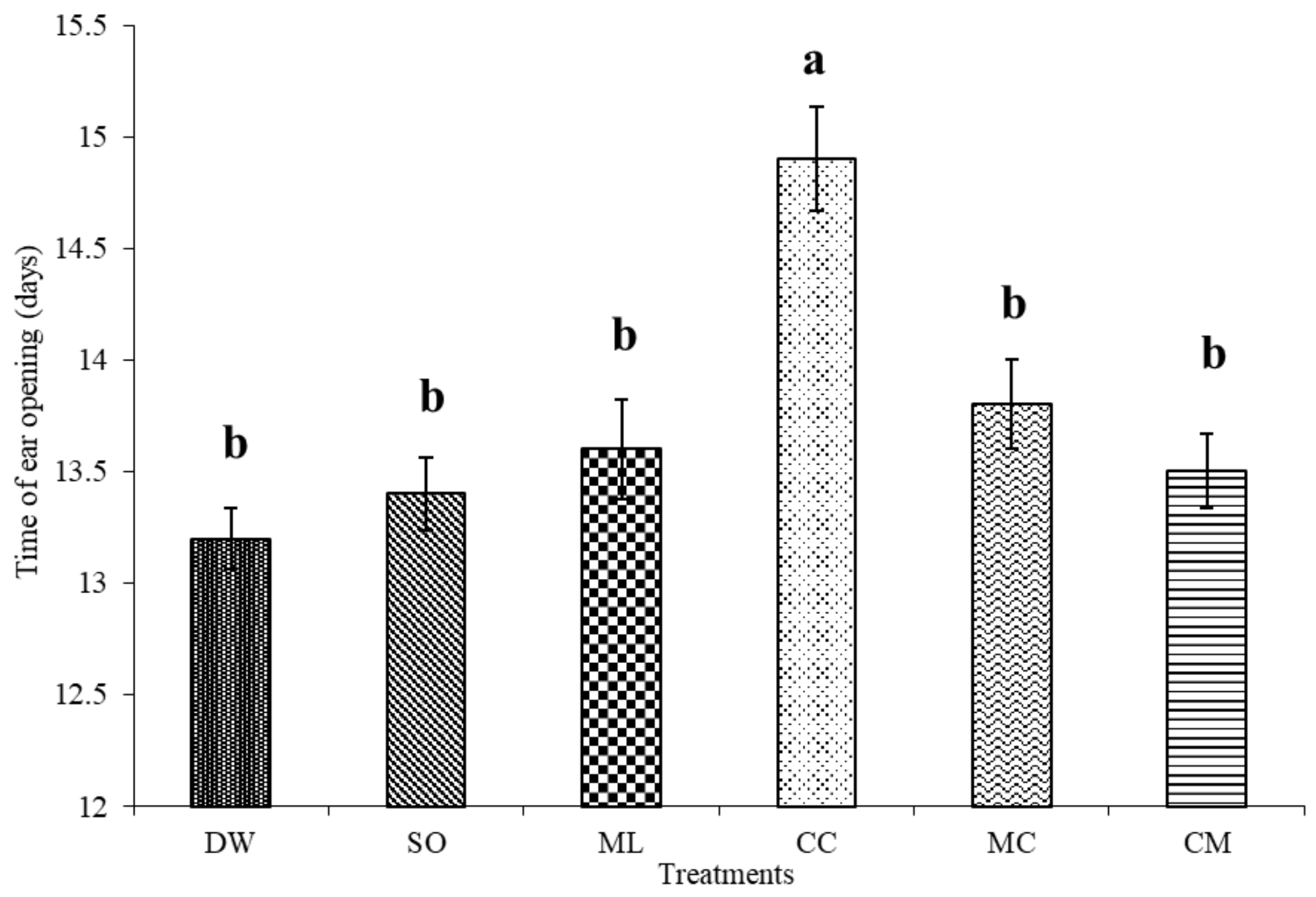

Figure 6

Effect of gestational and lactational exposure to Distilled water (DW), Soya oil (SO), Melatonin (ML), Chlorpyriphos and Cypermethrin (CC), Melatonin + chlorpyriphos + cypermethrin (MC) and Chlorpyriphos + Cypermethrin $+M L(C M)$ on Time of ear opening. $n=10$. Bars with different superscript differ significantly $(P<0.05)$. Results are expressed as \pm SEM. 


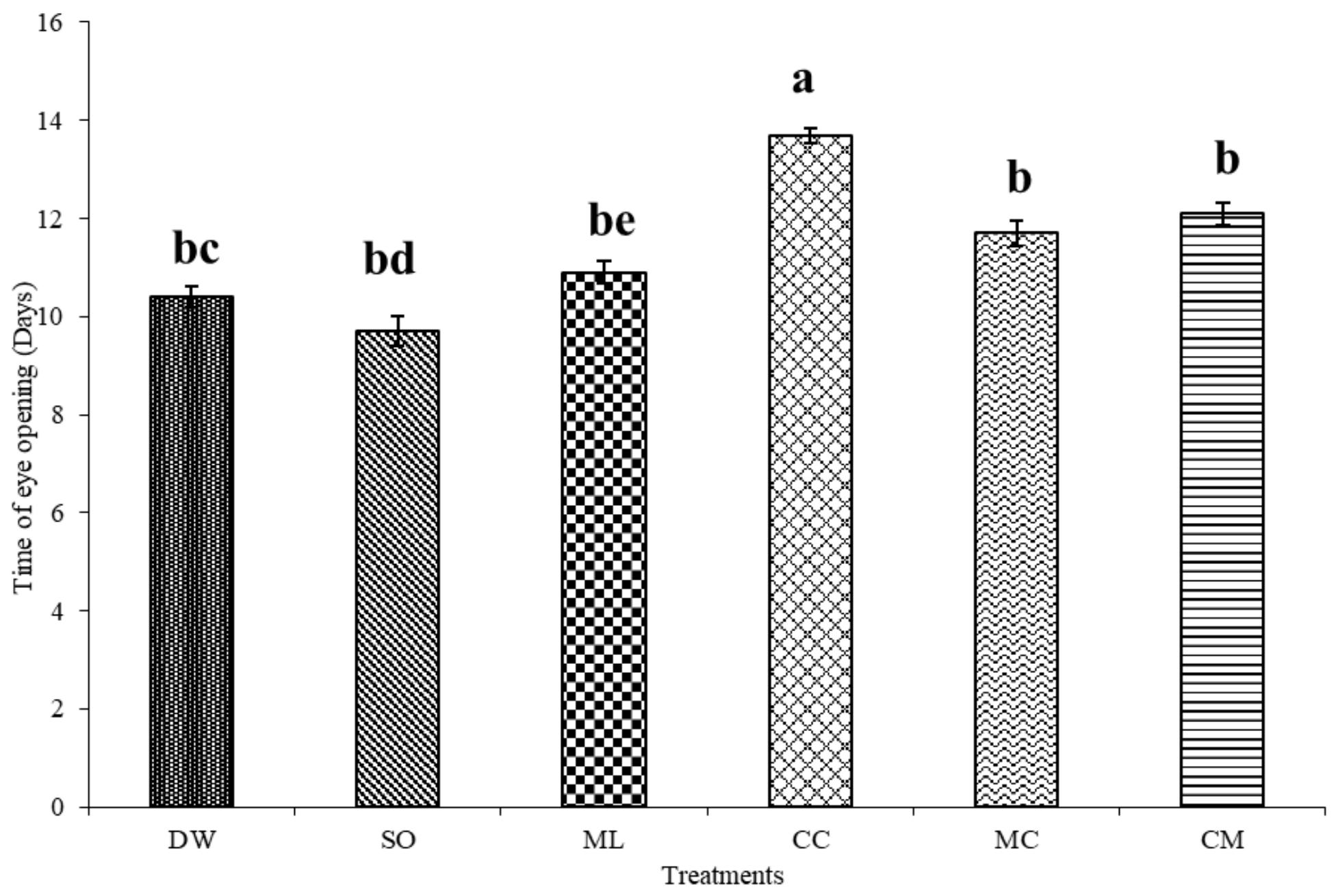

Figure 7

Effect of gestational and lactational exposure to Distilled water (DW), Soya oil (SO), Melatonin (ML), Chlorpyriphos and Cypermethrin (CC), Melatonin + chlorpyriphos + cypermethrin (MC) and Chlorpyriphos + Cypermethrin $+\mathrm{ML}(\mathrm{CM})$ on time of eye-opening. ${ }^{\mathrm{a}} \mathrm{P}<0.05$ versus $\mathrm{DW}, \mathrm{SO}, \mathrm{ML}, \mathrm{MC}$ and $\mathrm{CM}$ groups, respectively. $\mathrm{n}=10$. Bars with different superscript differ significantly $(P<0.05)$. Results are expressed as \pm SEM. 


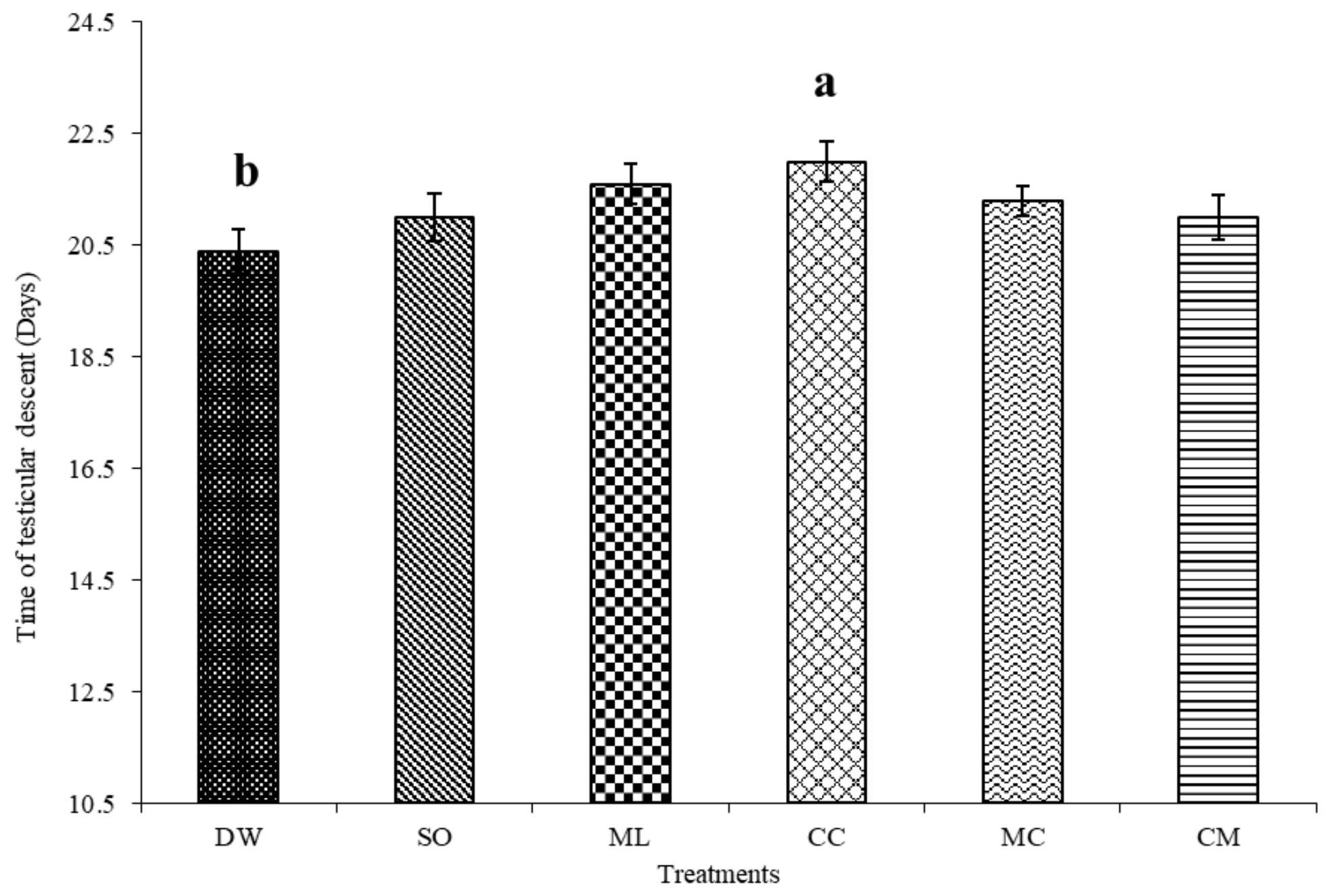

Figure 8

Effect of gestational and lactational exposure to Distilled water (DW), Soya oil (SO), Melatonin (ML), Chlorpyriphos and Cypermethrin (CC), Melatonin + chlorpyriphos + cypermethrin (MC) and Chlorpyriphos + Cypermethrin $+M L(C M)$ on time of testicular descent. $n=10$. Bars with different superscript differ significantly $(P<0.05)$. Results are expressed as \pm SEM. 